\title{
A MEIA-IDADE DA MULHER
}

\section{Teresa Fagulha ${ }^{1}$}

A escolha deste tema, recente e pouco estudado, levanta várias questões: será a meia-idade uma fase específica, que mereça uma abordagem particular? E haverá características próprias da vivência feminina desta fase, para além, evidentemente, da menopausa? Afinal, que idade é esta? Quais os marcos que a assinalam? Porque o tempo organiza-se e define-se por marcos, tem uma realidade objectiva que o relógio e o calendário apontam. Será o período que decorre entre os 40 e os 65 (critério comum na investigação), ou algum ponto de viragem algures nesse período? A que se refere esse "meia"? A metade do caminho da vida? Os 40 anos poderão acertar com esta versão, mas não certamente os $50 \mathrm{e}$, muito menos, os 65! Vem então a ideia de um relógio social (Neugarten, 1977) cujos ponteiros apontam o tempo certo para que determinados acontecimentos e tarefas de desenvolvimento ocorram, na família (filhos criados, "ninho vazio") e no trabalho (carreira estabelecida). Há ainda um relógio biológico que assinala o passar do tempo no nosso corpo e nas suas funções, relógio que por vezes nos desperta inesperadamente - tal é a forma como Helen Deutsch (1967) descreve a constatação da menopausa, um "já é demasiado tarde" que, para lá do biológico, apela a um tempo subjectivo ou existencial. Esse tempo, experimentado e vivido por cada um, integra a vivência psicológica de todos os outros tempos e relógios, dando um significado único ao correr da vida, que transcende os acontecimentos enquanto marcos objectivos na definição desta fase. Esta definição liga-se fundamentalmente a dois processos internos e interligados, desencadeados pelas circunstâncias de vida: a perda da ilusão da imortalidade (Jacques, 1965) e as revisões e reestruturações que a consciência do tempo limitado pressiona. De facto, a nossa vida teve um princípio e um dia terá um fim, mas é condição da nossa existência que vivamos o dia-a-dia sem a consciência dessa realidade. A ilusão de imortalidade das fantasias infantis, que guardamos no nosso inconsciente (e que têm um papel crucial na esperança em relação à vida) só é abalada quando a morte toca perto de nós, surgindo

\footnotetext{
${ }^{1}$ Professora Associada da Faculdade de Psicologia e de Ciências da Educação da Universidade de Lisboa. Centro de Psicologia Clínica e Experimental da Fundação para a Ciência e Tecnologia.
} 
sempre, de modo inesperado, e suscitando uma rejeição que necessita um duro trabalho de elaboração.

No meio da vida, os adultos confrontam-se com uma multiplicidade de experiências que apelam a reestruturações relacionais e concorrem para esta tomada de consciência da finitude da vida. Desde logo, o declínio e morte dos pais, no momento em que o próprio corpo dá sinais de perda de juventude. Os pais que precisam ser cuidados são uma estranha versão de filhos (Oldham, 1989), mas a caminho da morte e não da vida. Ao tornarem-se "pais" dos seus próprios pais, os adultos de meia-idade experimentam a perda de suporte da geração anterior, ao mesmo tempo que devem adaptar-se à emancipação dos filhos que, mesmo quando não saem de casa, já não são os filhos da infância, mas competem pelo poder e influência na família, tal como a sua geração compete pelo poder na sociedade. Os adultos de meia-idade ainda são quem frequentemente detém a responsabilidade na família e na sociedade, a geração que comanda - mas que fundamentalmente faz a ponte entre a geração dos mais velhos e a geração dos mais novos. São a "geração sanduíche" (Zal, 1993), estão no meio, e creio que é este o significado mais forte de meia-idade e meio da vida.

Os anos da meia-idade são fundamentalmente caracterizados pela experiência psíquica interna de confronto com a morte (a morte de que a geração anterior se aproxima), e por um balanço e avaliação da vida vivida, aquela que a geração dos mais novos está agora a atravessar. O tempo urge, há sonhos que já não se podem realizar, há sonhos realizados que não deram a satisfação esperada. O tempo urge, porque limitado. Elliot Jacques falou de crise da meia-idade: "A morte e a crise da meia-idade" (Jacques, 1965). A noção de crise tem sido questionada, fundamentalmente pela conotação negativa do termo, a que alguns autores opõem o de transição, uma das várias transições do percurso de desenvolvimento, envolvendo eventualmente um revisitar de problemas não resolvidos. Não parece que esta ideia se afaste da de crise adaptativa, que pode conduzir a uma experiência interna diferente pela elaboração de perdas - a perda de juventude, a perda de ilusões de omnipotência, fundamentalmente a de imortalidade, a perda dos pais e a aceitação da sua realidade, porque finalmente eles já não podem vir a ser como sonhámos. O que esta transição terá de particular face a outras já vividas é que abre caminho para a última parte da vida, através da reavaliação da vida passada. O balanço que dela se faz - mais positivo ou mais negativo - influi fortemente nos processos de elaboração e reestruturação que podem ou não ocorrer, e na capacidade de aceitação e adaptação ao envelhecimento.

Trata-se de um período de desafio, cujo estudo é essencial, numa perspectiva de intervenção e prevenção, porque muito se pode ganhar para pôr a render nos últimos anos da vida. Entender a meia-idade permite não 
só ajudar a viver melhor este período, mas todos os anos futuros, pois há ainda suficiente capacidade de força e investimento na vida para que se possam operar reestruturações. Paralelamente, pela sua colocação de charneira entre duas gerações adultas, a intervenção no adulto de meia-idade terá naturalmente consequências na sua relação com a geração dos mais velhos, mas também com a geração dos filhos e netos.

Finalmente, uma palavra sobre a especificidade da vivência feminina: a menopausa, enquanto marco biológico de finalização da actividade reprodutiva da mulher, limitação que o homem nunca irá experimentar, é o acontecimento mais marcante (e mais estudado) desta fase da vida da mulher. Do ponto de vista psicológico, ele foi abordado inicialmente pela psicanálise (desde Freud, se bem que muito pontualmente) e predominantemente por mulheres psicanalistas (para uma abordagem do tema na psicanálise, ver Laznik, 2003). No entanto, a menopausa só surgiu como área de estudo e investigação através do modelo médico que divulga a mensagem esperançosa da Terapia de Reposição Hormonal no combate aos sintomas físicos e psicológicos, a ela frequentemente associados. Quando a psicologia (nomeadamente, a psicologia do desenvolvimento e os estudos femininos) e a antropologia se interessaram pelo estudo da menopausa, veio a perceber-se que o modo como ela é vivida em diferentes culturas e grupos sociais tem enormes diferenças, as quais influenciam a própria experiência dos sintomas físicos (inclusivamente os que decorrem das alterações hormonais) e psicológicos, experiência que, afinal, não é universal. Torna-se, então, evidente que a compreensão da vivência deste fenómeno biológico necessita integrar variáveis psicológicas, sociais e culturais. $\mathrm{O}$ estudo destas variáveis tem tido um enorme desenvolvimento na identificação das atitudes em relação à mulher (no seus papéis feminino e materno), nos seus hábitos de vida e saúde, na sua história relacional, nomeadamente na sua função muito particular de "gestora" e responsável das relações familiares e intergeracionais. Assim, todos os marcos associados ao relógio social, atrás referidos, têm sido estudados no modo particular como afectam a mulher (e.g., o síndroma do ninho vazio), tal como os que se associam ao relógio biológico - reveladores e sinalizadores do envelhecimento - que, nas culturas ocidentais, penaliza de modo diferente a mulher, em relação ao homem. Estes estudos têm permitido ultrapassar uma visão predominantemente negativa da mulher de meia-idade, ou seja, da mulher na menopausa ou que dela se aproxima (deprimida, irritável, emocionalmente instável, não atractiva sexualmente), para uma óptica compreensiva dos desafios que esta fase de vida vem colocar e que podem conter a promessa de novos investimentos e realizações nos muitos anos de vida ainda disponíveis. 
Neste sentido, os artigos que integram esta revista abordam dois estudos sobre a mulher portuguesa: um estudo sobre os sintomas físicos e psicológicos (incluindo a sintomatologia depressiva) mais frequentes nos diferentes períodos da menopausa e a influência de variáveis sociodemográficas na ocorrência desses sintomas - artigo de Teresa Fagulha e Bruno Gonçalves, Menopausa, sintomas de menopausa e depressão: influência do nível educacional e de outras variáveis sociodemográficas; e um estudo sobre $A$ depressão nas mulheres de meia-idade: estudo sobre as utentes dos cuidados de saúde primários, de Bruno Gonçalves, Teresa Fagulha e Ana Ferreira. De facto, muito se tem afirmado a maior vulnerabilidade da mulher à depressão, bem como o aumento da sua ocorrência na fase da meia-idade. Esta questão é polémica e tem suscitado críticas por não integrar uma leitura do fenómeno depressivo que tome em consideração a relevância dos aspectos relacionais na organização da experiência feminina, nos seus valores e significados de vida. $\mathrm{O}$ pendor relacional que caracteriza o modo de ser feminino - "as mulheres crescem em conexão" (Jordan, Kaplan, Miller, Stiver, \& Surrey, 1991; Miller, 1976) -, e que é fundamental no seu papel materno, na família e na sociedade, surge como défice de autonomia e sinal de imaturidade quando analisado em função dum padrão masculino que valoriza a autonomia e independência como sinais de maturidade e saúde mental. Este artigo, que não é conclusivo sobre esta polémica, insere-se, tal como o anterior, numa linha de investigação em curso.

Um terceiro artigo, de Teresa Ribeiro, refere também dados sobre a população portuguesa: Casais de Meia-Idade - estudos com casais portugueses numa perspectiva sistémica. A autora aborda as tarefas de desenvolvimento da mulher, do homem e do casal no período da meia-idade da vida, assinalando a evidência de características idiossincráticas que permitem identificar diferentes tipologias na organização do casal, que estuda numa amostra de casais portugueses. Essas diferenças são ilustradas com extractos de entrevistas de casais de meia-idade.

Ainda no campo de estudo da menopausa, o artigo de Katherine Vaughn Fielder e de Sharon E. Robinson Kurpius, Marriage, Stress and Menopause: Midlife Challenges and Joys, analisa a relação entre a qualidade da relação conjugal e o stress na predição da sintomatologia menopausica. Esta análise revela que as mulheres com casamentos insatisfatórios, caracterizados por pior relação sexual, menos suporte social, menor profundidade na relação e maior conflito, referiram um aumento de stress e mais sintomatologia do que as mulheres com casamentos satisfatórios, não se encontrando diferenças devidas ao estatuto de menopausa. Estes resultados evidenciam que as variáveis relacionais podem ultrapassar em importância o estatuto de menopausa. 
Um último artigo, de Maria del Pilar Sánchez-López, Virginia Dresch e Violeta Cardenal-Hernáez, Relaciones entre salud física y psicológica en mujeres de mediana edad, insere-se no campo da Psicología da Saúde. Estuda as variáveis psicológicas (auto-estima, ansiedade - fisiológica, motora e cognitiva - e satisfação vital) que permitem predizer a saúde física (objectiva e subjectiva, ou autopercebida) das mulheres de meia-idade face às mulheres jovens, aos homens jovens e aos homens de meia-idade. Verificam que as mulheres de meia-idade têm piores índices de saúde objectiva e subjectiva, face aos três outros grupos, e constatam que é a ansiedade fisiológica (e não a auto-estima) que melhor prediz a Saúde Física, o que mostra a necessidade de programas de intervenção focados na sua diminuição. Também a análise da influência de variáveis demográficas nos índices de saúde das mulheres de meia-idade permite extrair conclusões que podem orientar as políticas de saúde.

\section{Referências}

Deutsch, H. (1967). La psychologie des femmes: Étude psychanalytique. Paris: Presses Universitaires de France. (Publicado originalmente em 1945).

Jacques, E. (1965). Death and the midlife crisis. International Journal of Psychoanalysis, 46, 502-514.

Jordan, J. V., Kaplan, A. G., Miller, J. B., Stiver, I. P., \& Surrey, J. L. (1991). Women's growth in connection. Writings from the Stone Center. Nova Iorque: The Guilford Press.

Miller, J. B. (1976). Toward a new psychology of women. Boston: Beacon Press.

Neugarten, B. L. (1977). Personality and aging. In J. E. Birren \& Schaie (Eds.), Handbook of psychology and aging (pp. 629-649). Nova Iorque: Van Nostrand Reinhold.

Oldham, J. M. (1989). The third individuation. Middle-aged children and their parents. In John M. Oldham \& Robert S. Liebert (Eds.), The middle years. New psychoanalytic perspectives (pp. 89-104). New Haven / Londres: Yale University Press.

Zal, H. M. (1993). A geração sanduiche: Entre filhos adolescentes e pais idosos. Lisboa: Difusão Cultural. 